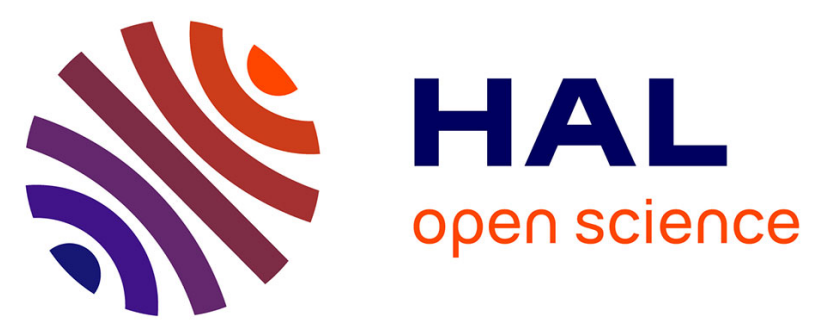

\title{
Quantitative Nano-amperometric Measurement of Intravesicular Glutamate Content and its Sub-Quantal Release by Living Neurons
}

Xiao-Ke Yang, Fu-Li Zhang, Wen-Tao Wu, Yun Tang, Jing Yan, Yan-Ling Liu, Christian Amatore, Wei-Hua Huang

\section{To cite this version:}

Xiao-Ke Yang, Fu-Li Zhang, Wen-Tao Wu, Yun Tang, Jing Yan, et al.. Quantitative Nanoamperometric Measurement of Intravesicular Glutamate Content and its Sub-Quantal Release by Living Neurons. Angewandte Chemie International Edition, In press, 10.1002/anie.202100882 . hal03262713

\section{HAL Id: hal-03262713 \\ https://hal.sorbonne-universite.fr/hal-03262713}

Submitted on 16 Jun 2021

HAL is a multi-disciplinary open access archive for the deposit and dissemination of scientific research documents, whether they are published or not. The documents may come from teaching and research institutions in France or abroad, or from public or private research centers.
L'archive ouverte pluridisciplinaire HAL, est destinée au dépôt et à la diffusion de documents scientifiques de niveau recherche, publiés ou non, émanant des établissements d'enseignement et de recherche français ou étrangers, des laboratoires publics ou privés. 


\title{
Quantitative Nano-Amperometric Measurement of Intravesicular Glutamate Content and of its Sub-Quantal Release by Living Neurons
}

\author{
Xiao-Ke Yang, ${ }^{1}$ Fu-Li Zhang, ${ }^{1}$ Wen-Tao Wu,${ }^{1}$ Yun Tang, ${ }^{1}$ Jing Yan, ${ }^{1}$ Yan-Ling Liu, ${ }^{1}$ \\ Christian Amatore, ${ }^{1,2,3^{*}}$ and Wei-Hua Huang ${ }^{1 *}$ \\ 1 College of Chemistry and Molecular Sciences, Wuhan University, Wuhan 430072 (China) \\ 2 State Key Laboratory of Physical Chemistry of Solid Surfaces, College of Chemistry and Chemical Engineering, Xiamen \\ University, Xiamen, 361005 (China) \\ 3 PASTEUR, Départment de Chimie, École Normale Supérieure, PSL Research University, Sorbonne University, UPMC Univ. \\ Paris 06, CNRS, 24 rue Lhomond, 75005 Paris (France)
}

\begin{abstract}
Glutamate (Glu) is a crucial fundamental excitatory neurotransmitter released through vesicular exocytosis in the central nervous system. Hence, quantitative measurements of intravesicular Glu and of transient exocytotic release contents directly from individual living neurons are highly desired for understanding the mechanisms (full or sub-quantal release?) of synaptic transmission and plasticity. However, this could not be achieved so far due to the lack of adequate experimental strategies relying on selective and sensitive Glu nanosensors. Herein, we introduce a novel electrochemical Glu nanobiosensor based on a single $\mathrm{SiC}$ nanowire prone to selectively measure in real-time Glu fluxes released via exocytosis by large Glu vesicles (ca. $125 \mathrm{~nm}$ diameter) present in single hippocampal axonal varicosities as well as their intravesicular content before exocytosis. Combination of these two series of measurements revealed a sub-quantal release mode in living hippocampal neurons, viz., only ca. one third to one half of intravesicular Glu molecules are released by individual vesicles during exocytotic events. Importantly, this fraction remained practically the same when hippocampal neurons were pretreated with L-Glu-precursor L-glutamine, while it significantly increased after zinc treatment, although in both cases the intravesicular contents were drastically affected. By affording quantitative measurements of intravesicular Glu inside living neurons and of its sub-quantal release fractions this work is opening new possibilities for investigating in situ and in time the regulatory mechanisms of glutamatergic neurotransmission and plasticity.
\end{abstract}

Keywords: glutamate (Glu), single nanowire electrochemical sensor, vesicular Glu content, subquantal release, release fraction.

Vesicular release of glutamate ( $\mathrm{Glu}$ ), a main excitatory neurotransmitter released in the central nervous system, is essential to ensure major brain functions such as cognition, memory and learning. ${ }^{[1]}$ Recent evidences based on indirect strategies propose that only part of Glu molecules stored in neuronal vesicles could be released through vesicular exocytosis. ${ }^{[2]}$ Confirming such indirect evidences is an important challenge considering that any modulation of vesicular release (i.e., partial or subquantal vs. full) is assumed to be an important factor associated to dynamic plasticity. Together with ascending regulation of the intravesicular content of neuronal vesicles, fine Glu-modulations are important for neural communication, memory, learning and metabolic regulation through their role on the synaptic communication efficiency of other neurotransmitters.[3] Therefore, direct, real-time, selective and quantitative monitoring of the characteristics of vesicular exocytotic Glu releasing events as well as independent knowledge of the initial intravesicular amounts of Glu are extremely important to understanding how neurons may adjust and coordinate their appropriate levels of excitability. However, direct in situ measurements of the intravesicular Glu content and of the amounts released 
during the corresponding individual exocytotic events could not be performed so far. In particular, the important issue of deciding unambiguously whether vesicular Glu release from single neurons is complete or sub-quantal could not be elucidated prior to this work.

Electrochemistry at microelectrodes and nanoelectrodes introduced significant possibilities for realtime monitoring of transient exocytotic events involving electroactive neurotransmitters and extracting quantitative and kinetic information with high spatiotemporal resolution.[4] For catecholamines and other related electroactive transmitters this permitted to demonstrate that subquantal release and "Kiss and Run" events are the major ones at single neurons and inside single functional synapses.[5] In this context, the IVIEC strategy (intracellular vesicle impact electrochemical cytometry) introduced by Ewing's group $[4 \mathrm{~g}, 5 \mathrm{~d}, 6]$ proved essential through offering an unique approach for measuring the mean total quantities of electroactive neurotransmitters stored inside individual vesicles in a cell before release occurs. Indeed the combination of these two types of measurements offers the only viable strategy for directly and unambiguously certifying the complete or sub-quantal quality of exocytotic vesicular release events from single living cells. However, both measurements require a nanosensor to selectively detect the released molecule.

Glu molecules being not electroactive, their electrochemical Faradaic detection requires modifying nanosensor surfaces with an enzyme such as glutamate oxidase (GluOx) prone to quantitatively and quickly convert Glu into an electroactive molecule such as $\mathrm{H} 2 \mathrm{O} 2$. GluOx-modified microelectrodes allows fast (i.e., sub-millisecond) quantitative measurement of Glu released in vivo by brain slices and single cultured neurons,[7] and have been shown to fulfill all requirements for vesicle impact electrochemical cytometry (VIEC) when applied to isolated vesicles.[2c]

Herein, we wish to report the first nanofabrication of a Glu bioelectrochemical sensor perfectly adapted to in situ measurement of vesicular Glu content by IVIEC inside varicosities as well as the vesicular exocytotic amounts released by living neurons (Figure 1). This nanosensor was obtained by immobilizing GluOx onto a CVD-carbon modified SiC commercial nanowire (SiC@C). CVD-carbon coating was necessary for allowing adequate electrical conductivity to the $\mathrm{SiC}$ insulating nanowire. However, since electrooxidation of $\mathrm{H} 2 \mathrm{O} 2$ at carbon material is difficult and sluggish, Pt nanoparticles (Pt-NPs) were electrodeposited onto the SiC@C surface before its modification with GluOx (Figure 1A).[8] This ensured fast and sensitive response to $\mathrm{H}_{2} \mathrm{O}_{2}$ (Figures S1A). To increase the loading and stability of GluOx onto the Pt-NPs surface areas, polyethyleneimine (PEI) with a strong positive charge and adequate biocompatibility and a crosslinker (PEDGE) were used. ${ }^{[9]}$ The successful immobilization of GluOx was characterized by Nicolet micro-FTIR (Figure S1B) and further evidenced by excellent electrochemical catalytic properties toward Glu oxidation (Figure 1B-C). A linear dependence at low Glu concentrations and saturation at high concentrations was observed, being consistent with enzymatic Michaelis-Menten kinetics. ${ }^{[10]}$ The nanosensor kinetic parameters obeyed a LineweaverBurk equation adapted to amperometric data (Figure S1C):

$$
\frac{1}{I}=\frac{K_{\operatorname{mapp}}}{I_{\max }} \cdot \frac{1}{[G l u]}+\frac{1}{I_{\max }}
$$

where $\mathrm{K}_{\mathrm{m}, \mathrm{app}}=0.22 \mathrm{mM}$ is the Michaelis equilibrium constant, and $\mathrm{I}_{\max }=83.3 \mathrm{pA}$ is the maximum value of the current response. The sensitivity and detection limits were $0.24 \mathrm{pA} / \mu \mathrm{M}$ and $4.16 \mu \mathrm{M}$, respectively $(\mathrm{S} / \mathrm{N}=3)$. [11] These values reveal that GluOx retained its excellent enzymatic activity after immobilization on the sensor. Furthermore, the high selectivity of this sensor was evidenced by comparing its high current responses for Glu with those of potential interferents (Figure S2). 
In addition, thanks to its cylindrical shape and its large aspect ratio this Glu nanoelectrochemical sensor is perfectly adapted to perform IVIEC measurements inside hippocampal axonal varicosities in living neurons for quantifying the mean intravesicular Glu content of individual vesicles (Figure 1D). Varicosities, the typical axonal sites where synapses may form, are reported to contain different types of vesicles.[12] Transmission electron microscopy (TEM, Figures 2A-a and S3) indicated that unpaired hippocampal varicosities (i.e., without any postsynaptic partner) are mostly equipped with large vesicles (LVs, Figure 2A-a; $123.6 \pm 3.0 \mathrm{~nm}$ in diameter, $\mathrm{n}=162$ ) whereas varicosities involved in synapses contained mostly small vesicles (SVs, Figure S3; $50.7 \pm 0.5 \mathrm{~nm}$ in diameter, $\mathrm{n}=171$ ).
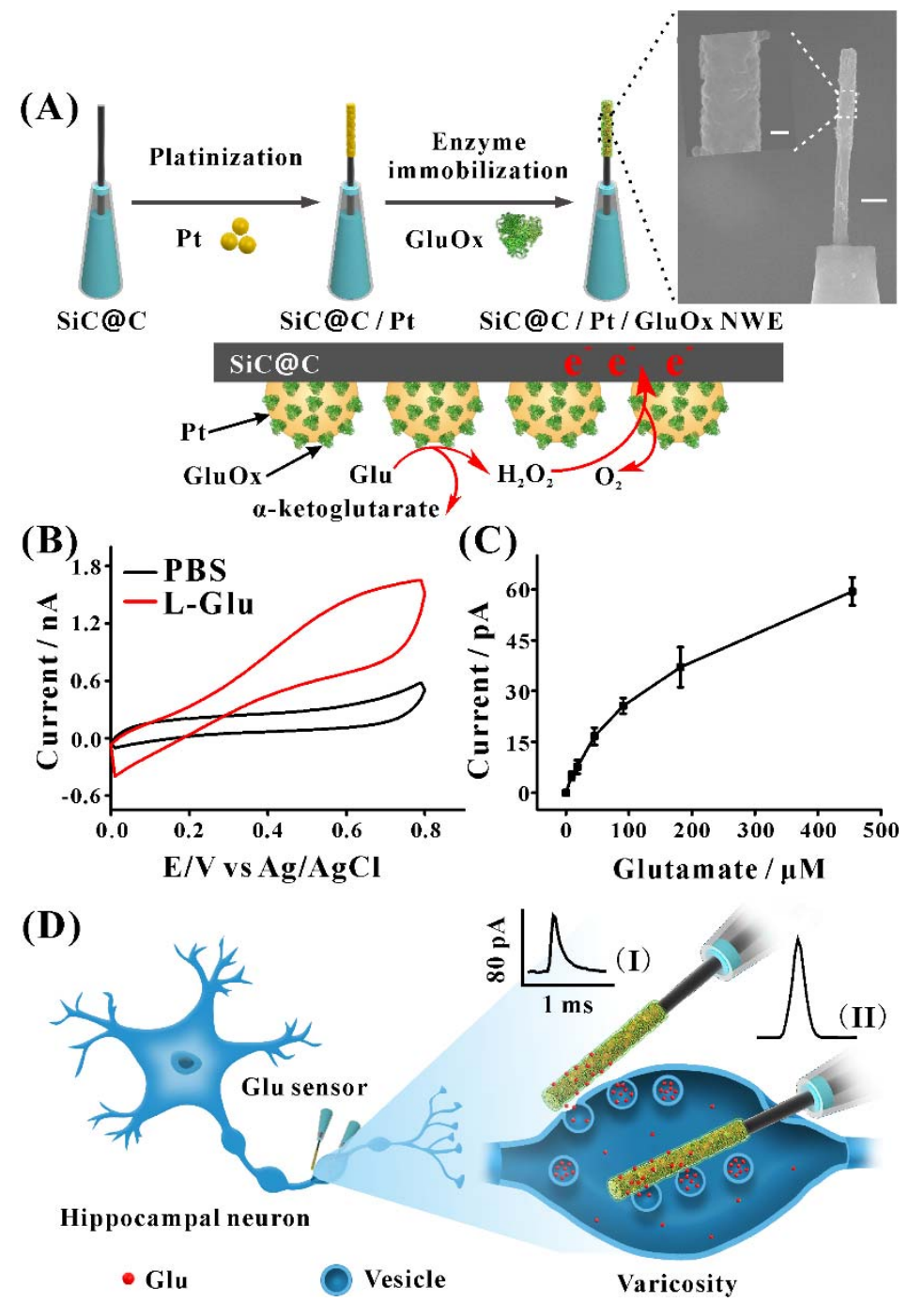

Figure 1. A) Schematic description of the fabrication of an electrochemical Glu-nanosensor from single SiC nanowire. Top cartoon sequence describes the fabrication process of a Pt/GluOx-modified SiC@C nanowire;

SEM image are shown in the inset on the right (scale bars $=1 \mu \mathrm{m}$ for the main view and $200 \mathrm{~nm}$ for the magnified one). Bottom scheme clarifies the mechanism of Glu electrochemical detection at the nanosensor surface. B) Cyclic voltammograms recorded at a single nanowire Glu sensor in PBS solution in absence (black) or in presence of $1 \mathrm{mM} \mathrm{L-Glu} \mathrm{(red).} \mathrm{C)} \mathrm{Calibration} \mathrm{of} \mathrm{the} \mathrm{Glu} \mathrm{nanowire} \mathrm{sensor} \mathrm{responses} \mathrm{to} \mathrm{a} \mathrm{series} \mathrm{of} \mathrm{Glu}$ concentration increments. Points on the plot represent mean \pm SEM of values obtained with three independent biosensors. D) Schematic showing the amperometric monitoring of vesicular Glu exocytotic release from a single varicosity of a hippocampal neuron (I) or intravesicular Glu content by IVIEC (II) depending on the placement of the nanoelectrode. 
The Glu nanosensor was first applied to detect exocytotic release from unpaired hippocampal axon varicosities. For this purpose, it was placed laterally onto the top of varicosities (see cartoon in Figure $2 \mathrm{~A}-\mathrm{b}$, Figure S4 and Figure S5). Release was elicited by high-K+ solution ( $62.5 \mathrm{mM})$ puffs, leading to a series of amperometric spikes (Figure 2B). No amperometric spikes could be observed when hippocampal neurons were stimulated in a Ca2+-free extracellular medium (Figure S6) or when SiC@C/Pt nanowires were not modified with GluOx (Figure S7). Therefore, the recorded trains of amperometric spikes unambiguously featured successive individual exocytotic Glu-release events. The most frequent type of spikes (Figure 2B-I; $46 \%$ occurrence frequency; single event) exhibited a shape similar to that most often observed for exocytotic events from endocrine cells[4a,5c] but the remaining other ones had complex shapes featuring a sequence of opening/closing phases of the fusion pore[5a,5b,5d] (Figures 2B-II-VI; see their relative frequencies in Figure S8 and Table S1) as previously reported before for individual Glu-release events recorded from brain slices.[2c,7c] Using Faraday's law, $\mathrm{Q}=2 \mathrm{FN}$ ( $\mathrm{F}=96500 \mathrm{C}$ is the Faraday constant, $\mathrm{Q}$ the peak electrical charge and $\mathrm{N}$ the total number of released molecules), statistical analyses evidenced that $\mathrm{N}=113,000 \pm 3,000$ molecules (mean \pm SEM, $n=243$ ) for simple events while ca. $50-70 \%$ more Glu molecules were released during complex events (Table S1). This observation along with the variety of current spike shape characteristics suggests the presence of a regulatory mechanism acting during exocytotic release prone to control the size, dynamics and lifetime of fusion pores in order to modulate Glu release during synaptic transmission in hippocampus.

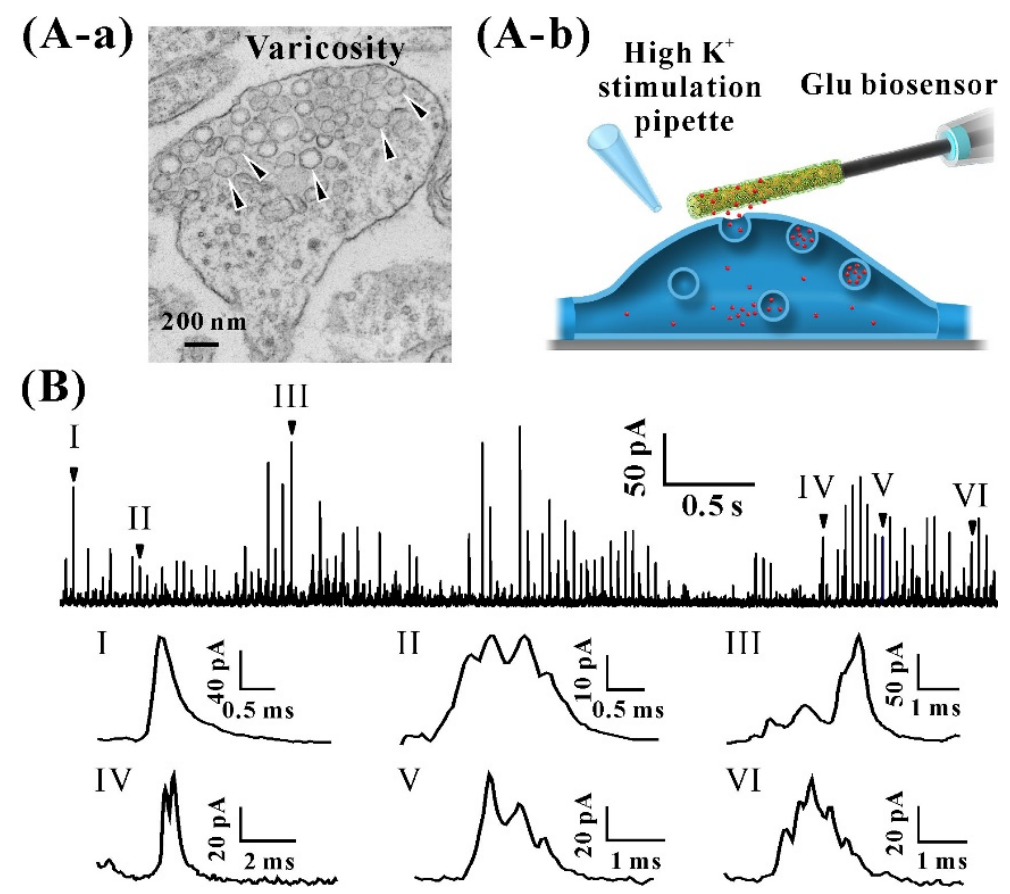

Figure 2. A-a) TEM of an unpaired hippocampal varicosity slice exhibiting vesicles (marked by arrows) with a mean diameter of $123.6 \pm 3.0 \mathrm{~nm}, \mathrm{n}=162$. A-b) Cartoon representing the amperometric monitoring of exocytotic vesicular Glu release from a single varicosity of a hippocampal neuron. B) Representative amperometric trace featuring a sequence of exocytotic events recorded from a varicosity stimulated with 62.5 $\mathrm{mM} \mathrm{K}+$ when the potential of the Glu sensing nanoelectrode was set at $+700 \mathrm{mV}$ vs $\mathrm{Ag} / \mathrm{AgCl}$ reference electrode while the nanosensor Glu-active tip was placed laterally in contact with the cell membrane (see panel A-b and compare to Figure $3 A$ when only the extremity of tip was place in contact with the membrane without $\mathrm{K}+$ stimulation). Different types of amperometric spike shapes are featured below the amperometric trace (523 events in total with relative frequencies of occurrence as shown in Figure S8 for this representative trace; see also Table S1 for statistical data): I: simple event; II-VI: complex events. 
Being able to compare intracellular vesicular neurotransmitter contents to the mean released quantities measured with a same nanosensor (Figure 2A-b) permits a facile, precise and unambiguous quantification of the mean released fractions. Such data are crucial for revealing and analyzing the factors influencing vesicular storage/release and investigating the regulatory mechanisms of synaptic plasticity.[5d,13] Owing to their excellent mechanical properties,[8a] the present nanowire Glusensors could easily penetrate through the varicosities membranes (Figure S9A) to perform measurements of intravesicular Glu content by IVIEC. The biologically inert [Ru(NH3)6]3+ redox cation was added into the PBS cell bath to report on the progression of the nanowire electrode through varicosities membranes while simultaneously certifying that they tightly resealed around the nanowire during and after penetration to maintain the cell homeostasis.[8] Rulll centers are reducible along the whole conducting surface of the nanowire (i.e., at Pt/GluOx-modified and unmodified zones of the whole conductive nanowire surface) but cannot cross through intact cell membranes due to their positive charge.[8] Hence, since ca. $40 \%$ of the nanowire surface area was modified by Pt/GluOx, a drop to $60 \%$ of the Rulll reduction current (compare curve 3 in Figure S9A; $n=15$ ) indicated that the whole Glu-sensing area was inserted inside the varicosity. After IVIEC measurements, more than $90 \%$ of the initial RullI reduction current value was restored upon withdrawing of the electrode (compare curve 4 in Figure S9A; $n=15$ ), indicating that the nanosensor electroactive surface was not significantly altered during its insertion or its permanence inside the varicosity.

No current transients could be detected in the absence of K+-stimulation when the Glu-nanosensor was positioned either laterally onto the varicosity membrane (compare to Figure 2A-b) or with its tip pressing against the membrane without penetrating through it (Figure 3A). Conversely, still without any $\mathrm{K}+$-stimulation, well-defined amperometric spikes were recorded when the sensor was inserted into the varicosity membrane as shown in Figure 3B. This set of experiments confirmed that the spikes featured the oxidation of Glu spontaneously unloaded by vesicles crashing stochastically onto the sensor surface (Figure S9B). Statistical analyses revealed that the total intravesicular Glu content obeyed log-normal distributions (Figure $3 C$ ) with Ntot $=361,000 \pm 3,000$ molecules (mean \pm SEM). Considering the average diameter $(123.6 \pm 3.0 \mathrm{~nm})$ of the large vesicles mostly present inside unpaired hippocampal varicosities (Figure 2A-a) i.e., their mean $980.0 \pm 56.7 \mathrm{zL}$ volume, a mean $0.60 \pm 0.03 \mathrm{M}$ intravesicular Glu concentration was deduced. This is approximately 2 to 9 times greater than what was previously estimated from radioreceptor assays or immunoisolation of synaptic vesicles from synaptosomes[14] but is similar to a recently reported concentration $(0.7 \pm 0.05 \mathrm{M})$ evaluated by electrochemical measurements performed on isolated Glu-containing vesicles. [2c] Compared to the number of released Glu molecules $(113,000 \pm 3,000)$ during simple exocytotic events this indicated that only one third of Glu molecules were released during simple vesicular exocytotic events. This released fraction increased up to ca. half of the total intravesicular content for complex events (compare Table S1). It must be emphasized that this strategy and the ensuing results afford the first fully coherent quantitative proof of sub-quantal release of Glu by living neurons during vesicular exocytosis. 

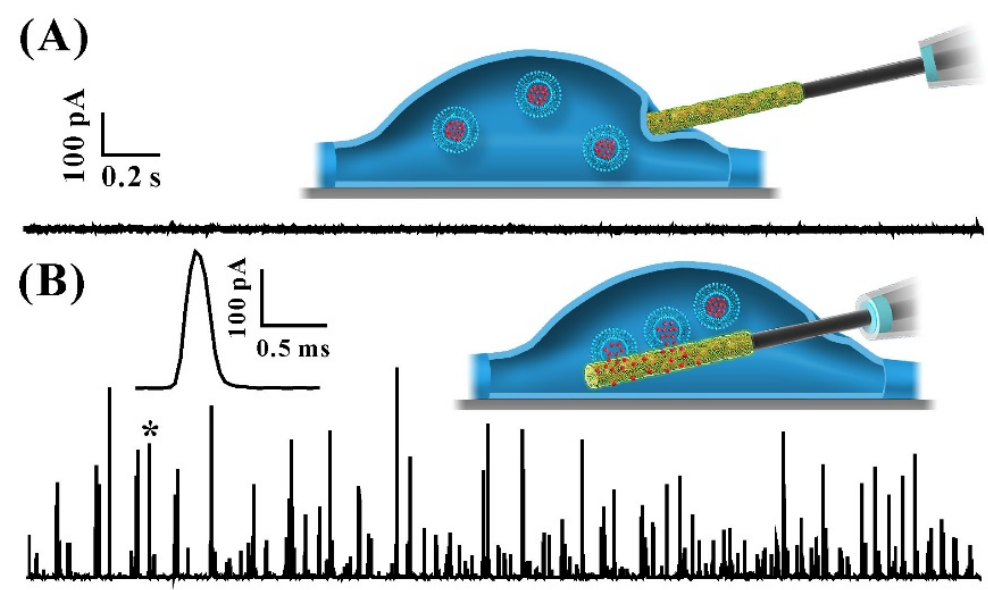

(C)

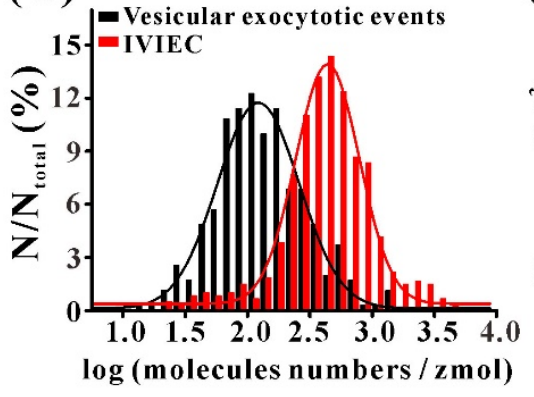

(D)

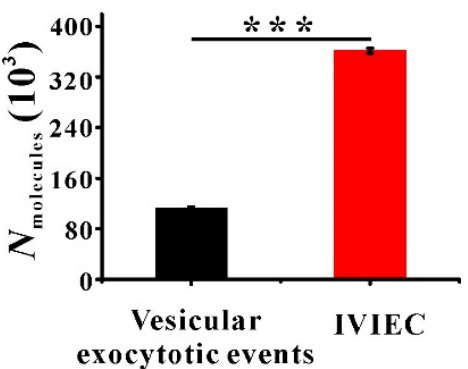

Figure 3. A, B) Representative amperometric traces when the Glu-sensing nanowire is placed against the varicosity membrane $(A)$ or inserted inside the varicosity $(B)$ in absence of $K+$ stimulation. The nanosensor potential was set at $+700 \mathrm{mV}$ vs $\mathrm{Ag} / \mathrm{AgCl}$ reference electrode. C) Normalized frequency histograms describing the distribution of the detected Glu amounts as quantified from hippocampal varicosities by IVIEC (red, $n=598$ events from 10 cells) or during $62.5 \mathrm{mM} \mathrm{K+-stimulated} \mathrm{exocytotic} \mathrm{release} \mathrm{(black,} n=351$ events from 15 cells).

D) Comparison of the mean numbers of Glu molecules released during vesicular exocytotic simple events or stored in intracellular vesicle (means \pm SEM), ${ }^{* * *} p<0.001$.

This prompted us to extend it in order to investigate if exocytotic Glu release and/or its intravesicular storage could be altered after incubating hippocampal neurons with L-glutamine (L-Gln) or zinc cations. Indeed L-GIn, a direct biochemical Glu precursor, and $\mathrm{Zn} 2+$ are reported to be involved in learning and memory process.[1b,15] $\mathrm{Zn} 2+$ is known to be stored in synaptic vesicles and closely involved in neurotransmission, while the zinc transporter 3 (ZnT3, a membrane protein) which regulates synaptic-vesicle zinc content and acts on Glu transporters in a Zn-dependent manner.[16] $\mathrm{Zn} 2+$ has also recently been shown to strongly affect exocytotic release and storage in neurotransmitter-containing vesicles of PC12 endocrine cells.[13a]

After incubation with L-Gln intravesicular Glu content and released amount significantly increased by ca. $259 \%$ (Ntot $=934,000 \pm 7,000$ molecules, $n=222$ ) and $183 \%(N=271,000 \pm 2,000$ molecules, $n=$ 144), respectively. Remarkably, the fraction of released Glu (29\%) remained almost unchanged vs. controls (Figure 4C-D). As expected L-GIn significantly improved the synthesis and intravesicular loading of Glu, but did not significantly affect the final fusion pore size[17] (Table S2). Contrastingly, $\mathrm{Zn}$ treatment caused a $42 \%$ decrease of the intravesicular Glu content (Ntot $=209,000 \pm 3,000$ molecules) but increased the number of released Glu molecules by ca. one third ( $N=148,000 \pm 3,000$ molecules) reaching then ca. $70 \%$ of the vesicle content (Figure 4C-D). Most presumably, treatment 
with $\mathrm{Zn} 2+$ favored the formation of largest final exocytotic pores in agreement with the ca. $36 \%$ higher Imax values and ca. 50\% longer rise times compared with the control group[15d,17] (Table S2).

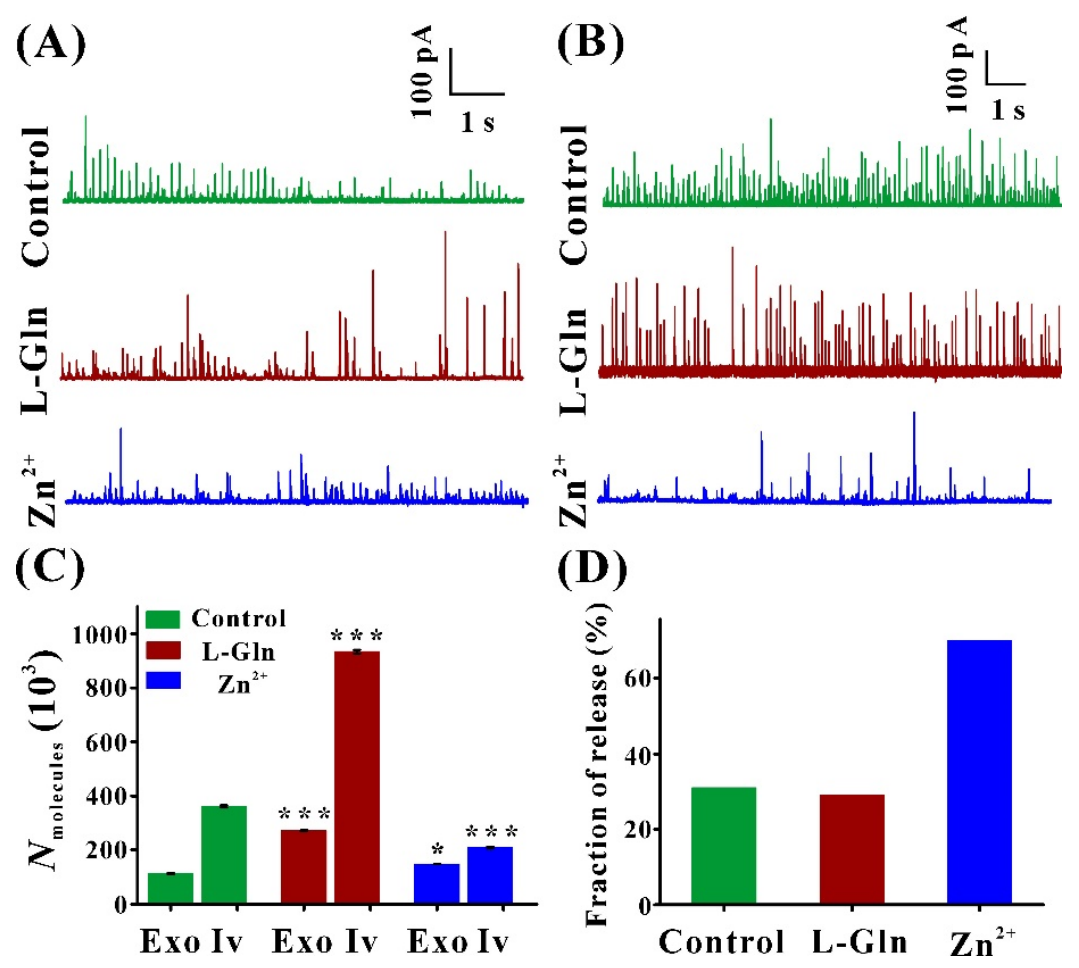

Figure 4. A, B) Representative amperometric traces featuring vesicular release during exocytosis (A) or recorded intracellularly with IVIEC (B) from single untreated varicosities (control) or treated with L-GIn (3 $\mathrm{mg} / \mathrm{ml}$ during $15 \mathrm{~min}$ ) or zinc (100 $\mu \mathrm{M}$ during $180 \mathrm{~min}$ ). C, D) Average number of Glu molecules (C) and released fractions (D) monitored under each condition. Vesicular release during exocytosis (Exo): $n=351$ events from 15 cells (control), $n=144$ events from 5 cells ( $L-G \ln$ ), $n=121$ events from 9 cells (zinc); IVIEC measurements (Iv): $n=598$ events from 10 cells (control), $n=222$ events from 5 cells (L-GIn), $n=212$ events from 10 cells (zinc). Error bars in C are the standard errors of the mean (SEM); ${ }^{*} p<0.05, * * * p<0.001$, relative to control.

In summary, taking advantage of the novel nanowire Glu bioelectrochemical sensor with high sensitivity and selectivity, good spatial-temporal resolution and superior mechanical toughness, the number of Glu molecules initially present or released by single vesicles from varicosities of living neurons could be determined to provide statistically significant information. These results unambiguously established for the first time that less than one third of intravesicular Glu molecules are released during simple events; even when release occurred by a sequence of opening/closing pore phases (complex events) this fraction could only increase to ca. one half. Additional investigations with this electrochemical Glu-nanosensor allowed investigating the role of L-Gln or Zn, two species closely involved in learning and memory mechanisms, on the intravesicular Glu content and the sub-quantal release fractions. These results further validate the concept of sub-quantal release during vesicular exocytosis by extending its generality from catecholamines to Glu.

Work is currently underway in our laboratories to take further advantage of this novel coherent strategy enabled by the present nanowire glutamate electrochemical biosensor to analyze 
quantitatively in real time the influence of Glu modulations on synaptic plasticity and some neuropsychiatric disorders.

\section{Acknowledgements}

We gratefully acknowledge financial support from the National Natural Science Foundation of China (Grants 21725504, 21675121, and 21721005), the University of Xiamen and the State Key Laboratory of Physical Chemistry of Solid Surfaces (PCOSS, University of Xiamen, China) through a Distinguished Scientist Chair awarded to C.A. In France, it was supported in part by PSL University, École Normale Supérieure, CNRS, and Sorbonne University (UMR 8640). Both teams gratefully acknowledge the CNRS Sino-French support (LIA "NanoBioCatEchem").

\section{References}

[1] a) T. V. Bliss, G. L. Collingridge, Nature 1993, 361, 31-39; b) B. S. Meldrum, J. Nutr. 2000, 130, 1007S-1015S; c) L. Volk, S. L. Chiu, K. Sharma, R. L. Huganir, Annu. Rev. Neurosci. 2015, 38, 127149.

[2] a) J. Klingauf, E. T. Kavalali, R. W. Tsien, Nature 1998, 394, 581-585; b) C. F. Stevens, J. H. Williams, Proc. Natl. Acad. Sci. U S A. 2000, 97, 12828-12833; c) Y. M. Wang, H. Fathali, D. Mishra, T. Olsson, J. D. Keighron, K. P. Skibicka, A. S. Cans, J. Am. Chem. Soc. 2019, 141, 17507-17511.

[3] a) E. T. Kavalali, J. Klingauf, R. W. Tsien, Philos. Trans. R. Soc. Lond. B Biol. Sci. 1999, 354, 337-346; b) R. H. Scannevin, R. L. Huganir, Nat. Rev. Neurosci. 2000, 1, 133-141; c) J. R. Whitlock, A. J. Heynen, M. G. Shuler, M. F. Bear, Science 2006, 313, 1093-1097.

[4] a) E. V. Mosharov, D. Sulzer, Nat. Methods 2005, 2, 651-658; b) W. Z. Wu, W. H. Huang, W. Wang, Z. L. Wang, J. K. Cheng, T. Xu, R. Y. Zhang, Y. Chen, J. Liu, J. Am. Chem. Soc. 2005, 127, 8914-8915; c) R. M. Wightman, Science 2006, 311, 1570-1574; d) A. Schulte, W. Schuhmann, Angew. Chem. Int. Ed. 2007, 46, 8760-8777; Angew. Chem. 2007, 119, 8914-8933; e) C. Amatore, S. Arbault, M. Guille, F. Lemaitre, Chem. Rev. 2008, 108, 2585-2621; f) M. Ganesana, S. T. Lee, Y. Wang, B. J. Venton, Anal. Chem. 2017, 89, 314-341; g) N. T. Phan, X. C. Li, A. G. Ewing, Nat. Rev. Chem. 2017, $1,0048$.

[5] a) Y. T. Li, S. H. Zhang, L. Wang, R. R. Xiao, W. Liu, X. W. Zhang, Z. Zhou, C. Amatore, W. H. Huang, Angew. Chem. Int. Ed. 2014, 53, 12456-12460; Angew. Chem. 2014, 126, 12664-12668; b) Y. T. Li, S. H. Zhang, X. Y. Wang, X. W. Zhang, A. I. Oleinick, I. Svir, C. Amatore, W. H. Huang, Angew. Chem. Int. Ed. 2015, 54, 9313-9318; Angew. Chem. 2015, 127, 9445-9450; c) A. Oleinick, I. Svir, C. Amatore. Proc. Math. Phys. Eng. Sci. 2017, 473, 20160684; d) A. Larsson, S. Majdi, A. Oleinick, I. Svir, C. Amatore, A. G. Ewing, Angew. Chem. Int. Ed. 2020, 59, 6711-6714; Angew. Chem. 2020, $132,6697-7002$.

[6] a) X. C. Li, S. Majdi, J. Dunevall, H. Fathali, A. G. Ewing, Angew. Chem. Int. Ed. 2015, 54, 1197811982; Angew. Chem. 2015, 127, 12146-12150; b) X. C. Li, J. Dunevall, A. G. Ewing, Acc. Chem. Res. 2016, 49, 2347-2354.

[7] a) Q. F. Qiu, F. L. Zhang, Y. Tang, X. W. Zhang, H. Jiang, Y. L. Liu, W. H. Huang, Electroanalysis 2018, 30, 1054-1059; b) M. Ganesana, E. Trikantzopoulos, Y. Maniar, S. T. Lee, B. J. Venton, Biosens. Bioelectron. 2019, 130, 103-109; c) Y. M. Wang, D. Mishra, J. Bergman, J. D. Keighron, K. P. Skibicka, A. S. Cans, ACS chem. neurosci. 2019, 10, 1744-1752; d) X. K. Yang, Y. Tang, Q. F. Qiu, W. T. Wu, F. L. Zhang, Y. L. Liu, W. H. Huang, Anal. Chem. 2019, 91, 15123-15129.

[8] a) X. W. Zhang, Q. F. Qiu, H. Jiang, F. L. Zhang, Y. L. Liu, C. Amatore, W. H. Huang, Angew. Chem. Int. Ed. 2017, 56, 12997-13000; Angew. Chem. 2017, 129, 13177-13180; b) H. Jiang, X. W. Zhang, Q. L. Liao, W. T. Wu, W. H. Huang, Small 2019, 15, 1901787; c) K. K. Hu, Y. L. Liu, A. Oleinick, M. V. Mirkin, W. H. Huang, C. Amatore. Curr. Opin. Electrochem. 2020, 22, 44-50.

[9] a) L. Mazzaferro, J. D. Breccia, M. M. Andersson, B. Hitzmann, R. Hatti-Kaul, Int. J. Biol. Macromol. 2010, 47, 15-20; b) Q. L. Liao, H. Jiang, X. W. Zhang, Q. F. Qiu, Y. Tang, X. K. Yang, Y. L. Liu, W. H. Huang, Nanoscale 2019, 11, 10702-10708.

[10] L. Michaelis, M. L. Menten, K. A. Johnson, R. S. Goody, Biochemistry 2011, 50, 8264-8269. 
[11] As evident from the data in Figures 2B and 3B (see also Table S2) several current spikes displayed current peaks intensities lying outside the linear range indicated by the Lineweaver-Burk equation in Eqn (1). Would the nanowire Glu sensor be used to monitor static or slow changing similar concentrations as performed during calibrations as in Figure $1 \mathrm{C}$, this would obviously create a problem since the amperometric current would underestimate the concentrations falling outside the biosensor linear range. However, in the present situation the sensor is used to monitor kinetically transient Glu quantities released during forced (IVIEC) or spontaneous (vesicular exocytosis) fast events separated by comparatively long periods during which no glutamate is present around the sensor (compare the traces shown in Figures 2B and $3 \mathrm{~B}$ ) so that the outcome is completely different. The present quantitative measurements involve the monitoring of transient concentration pulses (i.e., of fluxes) based on the total electrical charge exchanged per glutamate molecule globally oxidized at the electrode through the Glu-oxidase mediating enzymatic layer. These charges are determined by time integration of transient current spikes in which only the very narrow maximum current range exceeds the linear range of the sensor (compare the characteristic spikes shapes in Figures 2B or 3B) while most of charge exchanged during each event corresponds to the rising and descending branches of each current spike, i.e., when the electrochemical biosensor operates within its linear range. The brief concentration pulses around the spikes acute maxima range are nonetheless quantitatively detected over a few millisecond time delay (see section 1.7 in SI for a mathematical demonstration of this fact based on a radical but illustrative example). Hence, provided the time intervals between successive current spikes are large enough compared to the corresponding filtering time constant, the Glu quantities featured by each individual spike are quantitatively determined. This constraint is clearly fulfilled as evident through inspecting the typical traces shown in Figures 2B and 3B.

[12] a) M. Raastad, G. M. G. Shepherd, J. Physiol. 2003, 548, 745-752; b) N. E. Ziv, C. C. Garner, Nat. Rev. Neurosci. 2004, 5, 385-399; c) Z. Chiti, A. G. Teschemacher, FASEB J. 2007, 21, 2540-2550.

[13] a) L. Ren, M. D. Pour, S. Majdi, X. C. Li, P. Malmberg, A. G. Ewing, Angew. Chem. Int. Ed. 2017, 56, 4970-4975; Angew. Chem. 2017, 129, 5052-5057; b) C. Y. Gu, A. Larsson, A. G. Ewing, Proc. Natl. Acad. Sci. U S A. 2019, 116, 21409-21415; c) Q. W. Yue, X. C. Li, F. Wu, W. L. Ji, Y. Zhang, P. Yu, M. M. Zhang, W. J. Ma, M. Wang, L. Q. Mao, Angew. Chem. Int. Ed. 2020, 59, 11061-11065; Angew. Chem. 2020, 132, 11154-11158.

[14] a) N. Riveros, J. Fiedler, N. Lagos, C. Munoz, F. Orrego, Brain Res. 1986, 386, 405-408; b) P. M. Burger, E. Mehl, P. L. Cameron, P. R. Maycox, M. Baumert, F. Lottspeich, P. De Camilli, R. Jahn, Neuron 1989, 3, 715-720.

[15] a) C. J. Frederickson, S. W. Suh, D. Silva, C. J. Frederickson, R. B. Thompson, J. Nutr. 2000, 130, 1471S-1483S; b) M. M. Black, J. Nutr. 2003, 133, 1473S-1476S; c) A. D. Ruiz, S. Montes, H. S. Ceballos, V. Maldonado, L. R. Espinosa, C. Ríos, Neuroreport 2016, 27, 1317-1322; d) L. Ren, A. Oleinick, I. Svir, C. Amatore, A. G. Ewing, Angew. Chem. Int. Ed. 2020, 59, 3083-3087; Angew. Chem. 2020, 132, 3107-3111.

[16] a) R. D. Palmiter, T. B. Cole, C. J. Quaife, S. D. Findley, Proc. Natl. Acad. Sci. U S A. 1996, 93, 1493414939; b) S. Gloria, C. Branch, L. Rachal, K. Daniel, F. Victor, J. Cell Sci. 2005, 118, 1911-1921.

[17] a) R. Hu, B. Ren, C. J. Lin, A. Oleinick, I. Svir, Z. Q. Tian, C. Amatore. 2016, J. Electrochem. Soc. 163, H853-H865; b) A. Oleinick, R. Hu, B. Ren, Z. Q. Tian, I. Svir, C. Amatore, J. Electrochem. Soc. 2016, 163, H3014-H3024. 